\title{
A systematic approach to investment risk management using the example of the Rostov region
}

\author{
Irina Terenina \\ Don State Technical University, \\ Civil engineering and architecture Academy \\ Faculty of information and economic systems \\ Chair of Economics, Management and Logistics \\ in Construction \\ Rostov-on-Don, Russia \\ terenin@yandex.ru
}

\author{
Natalya Osadchaya \\ Don State Technical University, \\ Civil engineering and architecture Academy \\ Faculty of information and economic systems \\ Chair of Economics, Management and Logistics \\ in Construction \\ Rostov-on-Don, Russia \\ terenin@yandex.ru
}

\author{
Evgenia Mikhailichenko \\ The Customs Academy (Rostov branch) \\ Chair of foreign languages \\ Rostov-on-Don, Russia \\ terenin@yandex.ru
}

\begin{abstract}
This article considers the problems of management in the process of realization of investments projects on the regional level. Taking into consideration the specific features of Rostov region, the risks were considered from the systematic approach. It will help to create effective risk management system. It was made the conclusions about the necessity of formation of the single system of effective measures to overcome negative consequences of every element from revealed complex of risks. The program of managing the risks being embedded in the general system of accepting the managing decisions provide additional, subordinate character concerning the main strategy of the region.
\end{abstract}

Keywords - investment risks, development of the region, system approach

\section{INTRODUCTION}

Business decisions are always made under uncertainty, i.e. when information is incomplete or unreliable. This becomes more complicated issue when analyzing and predicting risks associated with investment projects. Because their implementation is a significantly timed process, it only adds to uncertainty in the internal and external environment. The current importance of managing risks involved in the implementation of an investment process stems from high tangible costs, variable characteristics of inputs and outputs, and the impact of external and internal factors that cannot be anticipated or predicted based on available data. Some of the external factors that one should take into account include a stronger competition, a rise in inflation, a fall in investment, and other consequences of the financial crisis. For instance, investment in fixed capital as a measure of business activity across Russia has decreased by $2.3 \%$ over 2016; retail turnover has reduced by $5.3 \%$; and foreign trade turnover has fallen approximately by $16.5 \%$ over the same period. All these things give an indication that the economic climate is weak [1].

Rostov region relates to the number of leading industrial regions of Russia. The proportion of industry in gross regional product is more than $22.0 \%$. The proportion of investments in the main capital in the structure of the same index in Rostov region is $2.0 \%$, Southern Federal District is 24.1\%. [2] However, investment is a factor contributing to an effective and competitive economy. The prospect competitiveness of Rostov region which is defined on the base of the volume of investments in the main capital corresponds to the $12^{\text {th }}$ place: volume of investments in the main-capital of Rostov region due to the actual prices in January-February 2016 were $297480.7 \mathrm{mln}$. rubles.

Examining a variety of ways in which Russian and foreign scholars $[3,4,5,6,7]$ have addressed the issue in question, one may reasonably conclude that further work needs to be done to improve the efficiency of risk management based on a systematic approach. 


\section{MATERIALS AND METHODS (MODEL)}

Research methods included dialectics and analytics, system analysis, induction and deduction, mathematical modeling in economics, statistics, expert evaluation, scenarios, brainstorming, etc.

\section{RESULTS AND DISCUSSION}

This paper identifies some factors that affect the decisions managers make with respect to risks associated with the implementation of investment projects. Requirements, principles, and a goal tree of a risk management system have been laid down so that a corporate growth strategy can be developed to manage the investment process effectively at the regional and enterprise level.

Using a systematic approach to determine the causes of risks in the internal and external environment and choosing the best methods for their assessment will enable one to develop an effective investment risk management system.

Over the years, scholars and practitioners have been interested in the study of risks that investment projects involve. In 2009, the Bulletin of the Lobachesvky University of Nizhny Novgorod published an article titled "A system of eliminating risks in a regional investment process" by E.A. Kosovskikh, A.A. Kosovskikh, and Yu.V. Trifonova who proposed a public private partnership model for eliminating risks that arise within the regional investment process.Risk reduction tools for the implementation of investment projects in the animal products sector was a paper published on the same topic by N.B. Guber, M.B. Rebezov, and G.M. Topuria in theBulletinofSouthUral State University. Risk analysis in an investment and construction project was another paper published by A.A. Skiba and A.V. Ginzburg in the Bulletin of Moscow State University of Civil Engineering.

The papers by Hastak M., Shaked, John J. Hampton, Kapila P., Hendrickson C., Kerzner H. and others are considered different aspects of managing specific types of commercial risks. None of the papers, however, addressed a systematic approach to risk management. It would provide a comprehensive response to the impact of the ever-changing environment which is particularly important when implementing investment projects given their time span.

While carrying out investment projects, investors and building contractors face a whole range of challenges involving risks that compromise the achievement of targets. Such challenges included administrative barriers, corrupt and hidebound authorities, alack of information, limited internal resources, a poor regulatory and legal framework, and serious economic risks.

To provide further details on the definition of risk, it is reasonable to identify the concept of "risk situation" because it is directly linked to what the term "risk" denotes. "Situation" can be defined as a set, or combination of circumstances or conditions that provide a particular environment for an activity. Notably, the environment may be conducive to or may hinder the implementation of such an activity. Of particular interest among different types of situations is a risk situation. Uncertainty is an integral part of the functioning and development of many economic processes. This gives rise to situations without a definitive outcome (solution). If the degree to which a scenario is likely to happen may be quantitatively and qualitatively measured, that makes a risk situation. Hence, a risky situation has to do with statistical processes and has three concomitants. First, the existence of uncertainty. Second, the need to choose an alternative (it should be noted that the refusal to choose is also a kind of choice). Third, the opportunity to assess the likelihood of alternatives chosen. Interestingly, the situation of risk is substantially different from that of uncertainty. The latter is marked by the fact that whether the outcome of decisions or events is likely to occur cannot be determined. Thus, a risk situation may be described as the kind of uncertainty when the occurrence of events is probable and can be determined. Specifically, there is a real opportunity to assess the likelihood of events that may result from industrial cooperation between partners, counteraction of rivals or opponents, environmental impact on economic progress, the adoption of scientific and technological advances, etc.

Whatever the cause may be of economic risk, any agent naturally wishes to reduce possible losses due to that risk. This can be done by making management decisions, whereby risks are managed. Risk management is the process of making and fulfilling management decisions that reduce the negative impact of losses on a business due to fortuitous events.

1. A systematic nature of risk management suggests that a set of risks are considered comprehensively as a whole, including any relationship and implications. Apart from seeing the big picture, one can take into account not only the effect of risk management tools on a risk they are meant to deal with, but also their effect (positive or negative) on other risks depending on the place and connections they have within the system and the emergence of new risks.

2. A complex structure of the risk management system. This property implies not only the need to analyze a great number of different kinds of risks simultaneously, i.e. a largely heterogeneous set of risks, but also the specific interdependence of risks and the possibility of using it to solve problems of various grades. Furthermore, this property involves studying the nature and the degree to which a multitude of factors affect the unfolding of a risky situation and the occurrence of adverse consequences. Such study would have to include the following aspects of the risk management system. First, versatility and flexibility, i.e. the ability to deal with different kinds of risks and the consequences they result in. Second, modularity, i.e. the possibility to apply different combinations of risk management procedures to a variety of situations, which enables one to take into account the specifics of a situation and adjust the system to meet the user's individual needs, if required. Third, a multitier framework, i.e. providing a suitable hierarchical decisionmaking structure that ensures that authority and responsibility are assigned appropriately.

3. Great efficiency of $\mathrm{t}$ he risk management system. This property reflects the ability of a set of measures explored to reduce the likelihood of adverse events and/or overcome their consequences. Apparently, said system must promptly respond to changing conditions, i.e. it must have an elaborate feedback loop. In addition, it must generate and implement viable 
solutions with a focus on achieving intended results in a prompt manner (reduction of economic losses).

In order to meet these requirements, it is assumed that the risk management system should conform to such aspects as responsiveness and adaptability, i.e. the ability to adapt to a rapidly changing environment, rapid response, and the ability to promptly handle negative situations; appropriateness, i.e. the relevance of implemented risk management procedures to a specific situation, which manifests itself in the ability to promptly allocate any resources required to achieve the set objectives; and efficiency, i.e. the ability to overcome the negative consequences of untoward situations with the least amount of resources. In particular, the risk management system must provide a net benefit meaning that after risk management procedures and methods have been implemented ,risk management expenses and the extent of possible loss should be less than potential loss before steps have been taken to protect a firm from risk. Thus, risk management has all the characteristics to qualify as an isolated system, which demonstrates that it can and needs to be used.

The above mentioned principles of risk management are common and universal. However the risk management system has some features specific to the object, goals, and methods of management, which is reflected in the fundamental principles underlying risk management.

Fundamental principles of region risk management may include:

- a risk management system is should be in conformity with the region's development strategy and institutional features of its operation;

- the features of a risk management system affect its goals and objectives, which suggests that decision making has a highly specialized nature within the system;

- external and internal constraints should be considered when managing risks, which means that relevant special measures are consistent with a firm's operating capabilities and environment;

- a unified risk management policy should be pursued with respect to the whole spectrum of risks, which requires comprehensive and simultaneous management of any risks;

- risk management is a dynamic process due to the nature of risk management decisions made on a continuous basis.

These fundamental principles characterize the features of a risk management system and are basically always evident in practice. However they can be implemented differently in specific contexts. Let us consider the principles in greater detail for a deeper understanding.

The relationship between a region's development strategy and a risk management system is evident not only in the fact that the former determines the latter, but also the availability of feedback. That is to say, the choice of a risk management alternative may require that the strategy be adjusted in some way or specific risks be considered in advance in the course of its development. When a region's goals and mission cannot be implemented, its strategy must be adjusted to take account of any possible circumstances.

In terms of a systematic approach, one has to define the purpose of the risk management system. The main purpose is to ensure that a region operates successfully in an environment of risk and uncertainty. This means that even in the event of economic loss, the implementation of risk management measures must enable a region to continue with its transactions, ensure their stability and sustainability of respective cash flows, maintain its profitability and growth, and meet any other targets. Thus, while integrated into the shared management decision making system, the risk management program is ancillary or subordinate to a firm's core business.

The investment's risk management system has a number of auxiliary purposes in addition to the main one.

First and foremost, these are the following:

- ensuring transaction efficiency. The achievement of this purpose means cost savings with regard to incidental loss, i.e. it involves higher costs of risk management measures to protect from excessive losses, albeit incurred with a slight possibility;

- establishing an appropriate degree of uncertainty with respect to possible loss. This purpose suggests that risk is reduced to an acceptable level unless it can be completely avoided;

- legitimacy of actions. This purpose is of great importance. While illegal actions may protect from some risks, they will give rise to other risks, thus making this approach inconsistent with the main purpose of the risk management system;

- other purposes. The scope and content of such purposes depend on the specifics of business protected and risk management measures. An example could be humanitarian agenda, i.e. proposed measures meet socially acceptable ethical standards. Thus, depending on the specifics of risks and measures to manage them, there is a hierarchy of purposes within the risk management system. Yet, these purposes are in a more complicated relationship rather than a simple hierarchy.

Therefore, when a system of risk management purposes is developed, the following additional requirements should be met:

- one should determine the extent to which the purposes need implementing, i.e. prioritize them;

- one has to assess the need for resources to meet purposes. Delivery of some purposes demands more effort and resources than other ones, so it is important to take this fact into account to appreciate the potential of the risk management system and its purposes;

- one should consider the relationship and contradictory nature of purposes, i.e. allow for the fact that accomplishing some purposes may facilitate or hinder the accomplishment of other ones. To put it differently, consideration of inherent 
connections between the purposes explored improves the efficiency of the whole risk management system.

The risk management system cannot operate successfully unless account is taken of constraints of the external environment and features specific to its dynamics. Such constraints may be evident in the following ways:

- statutory restrictions. Such external constraints may appear in the form of laws or regulations that reflect microand macroeconomic regulation methods. For instance, a firm's duty to comply with tax legislation or government requirements for occupational safety are examples of microeconomic regulation. Macroeconomic regulation includes but is not limited to environmental protection requirements.

- restrictions related to obligations of and to contractors.

This form of constraint represents horizontal, or market restrictions. These are attributable to macroeconomic processes and the specific development of markets.

Internal constraints may include:

- institutional restrictions, i.e. restrictions have a significant impact on risk management decision making in the sphere of management(for example, some features of management may affect the choice of risk management methods);

- budgetary restrictions, i.e. the limitations of funding available for risk management measures. Therefore, the scope of the measures will be defined based thereon;

- information restrictions, i.e. decision making can be affected by a shortage of information, which may be evident both in the amount and scope of available data. A lack of information or errors in its content lead to wrong risk management decisions.

\section{CONCLUSION}

Generally, in the process of realization of investments projects at the regional level, management is exposed not to a single risk but a wide range of risks. That is to say, risk management must ensure a framework of effective measures to deal with negative consequences of each item within the range, i.e. provide comprehensive control over the whole range, or a portfolio of risks.

This requirement leads to the point where risks are examined at two levels:
- analyzing risks individually to make it possible for a risk manager to understand the specifics of a risky situation or that of its negative outcome. Such an analysis provides an opportunity to choose the instruments that are best suited to managing each specific risk;

- analyzing the whole portfolio of risks to assess the overall effect of risks on the firm concerned. Such an integrated representation of a set of risks, and the manner in which it is recorded are referred to as risk profile and risk passport, respectively.

The risk management system must rely on both levels and include instruments and methods specific to each of them.

Using a systematic approach to determine the causes of risks and choosing the best methods for their assessment will enable to develop an effective risk management system. These recommendations can be put into practice by investors, customers, design and construction organizations, and building maintenance organizations, and may be of value to researchers, teachers, postgraduate and graduate students studying Management.

\section{References}

[1] A systematic approach. Moscow Witte University Bulletin. Series 1: Economics and management, 2012, i. 1(1). Available at: https://www.muiv.ru/vestnik/pdf/eu/eu_2012_1_65_71.pdf

[2] Rostov region in figures. 2016 [Rostovskaya oblast' $v$ tsifrakh]. 2016: Stat.sb./Rostovstat. - Rostov-na-Donu, 2017. - 760 p. URL: http://rostov.gks.ru/wps/wcm/connect/rosstat_ts/rostov/ru/publications/o fficial_publications/electronic_versions/

[3] Berdnikova L.F., Fatkullina E.R. The financial crisis of 2014-2015 and its impact on Russia.Molodoiucheny, 2015, no. 11.3, pp. 10-13. Available at: https://moluch.ru/archive/91/19713/ (Accessed 8 May 2017)

[4] Boldyreva N.B. [Stoimostnoi podkhod k integrirovannomu upravleniyu riskami kollektivny khinvestitsion nykhfondov.] Doct, Diss. [A value approach to the integrated management of risks in collective investment funds. Dokt. Diss.]. Yekaterinburg, 2011, 40 p.

[5] Gracheva M.V. [Riskanalysisofaninvestmentproject].Moscow, YunityDana Publ., 2001, 352 p.

[6] Retail turnover in Russia. Current status report by the Federal State Statistics Service.GazetaVedomosti, 2016.

[7] Osadchaya N.A., Bagdasaryan A.K. The specific system of managing risks for investment and construction projects in the Russian Federation. Nauchnoyeobozrenie [Scientificreview], 2013, no. 12, pp. 267-269. (in Russian)

[8] Terenina I.V. Analysis of uncertainties in supply chains.RISK: Resursy, informatsia, snabzhenie, konkurentsia [RISC: Resources, information, supply, competition], 2012, no. 2,pp. 95-97. (in Russian) 